\title{
THIRD WORLD CONGRESS OF ANAESTHESIOLOGY
}

The Scientific Programme of the Third World Congress of Anaesthesiology will be built around seven main topics, or Panel Discussions, namely

1 Problems of Anaesthetics in Developing Regioris (Charman Professor $\mathbb{R} \mathbb{R}$ Macintosh, Oxford, England)

2 Hypotension (Charman James E Eckenhof, Philadelphia, U S A )

3 Catecholammes and Therr Significance in Anaesthesid (Chanman Professor $\mathbb{R}$ Frey, Mainz, Germany)

4 The Need for and Functions of the Department of Anaesthesiology at the Hospital and at the University (Chairman Professor Juan A Nesi, Caracas, Venezuela)

5 The Mechanism of Action of Local Anaesthetics (Charrman Philip $\mathbb{R}$ Bromage, Montreal, Canada)

6 Clinical Use of Halogenaled Agents (Charman Lucien Morms, Seattle, U.S A)

7 Paediatric Anaesthesia for Correctable Congenital Anomalies (Charrman Digby Leigh, Los Angeles, U S A )

Also as part of the Scientific Programme, there will be two Symposia, respectrvely on

1 Neuroanaesthesia

Di $R$ G B Glbert, President

McGill University

3801 University Street

Montreal 2, Canada

Dr $\mathbb{H} \mathbb{R}$ Terry, Jr, Secretary

Mayo Clinic

Rochester, Minn, U S A

2 Anaesthesia for Cardiac Surgery with Extracorporeal Circulation

The Secretariate

III World Congress of Anaesthesiology

All detalls, data, instructions, and deadlines pertinent to the Scientufic Programme appear on the Registration Forms to be distributed to each anaesthetist of Canada by

University Tours Ltd

2 College Street

Toronto 2, Canada

Treasure Tours Inc

1010 St Catherine Street W

Montreal, Canada

These Travel Agents will also furnish to interested parties all information relating to travel and accommodation arrangements

For specific information please contact

The Secretarnate

III World Congress of Anaesthesiology

Cawa Postal 330

São Paulo, Brazll 